\section{Teledentistry: New Tool to Access Dental Care}

\section{QR CODE}

\section{ADITI VERMA ${ }^{*}$, AKSHAY DHALL', SAKSHI KATARIA $^{2}$}

The Health sector is undergoing dramatic revolution by incorporating the utilization of computers and telecommunications. Its Implications in hospitals and among physicians have gained attention. However, its impact on dentistry is less widely reported. Teledentistry can improve access to dental care as well can be used as a tool for dental education.

KEYWORDS: Telemedicine, Teledentistry, Dental Informatics, Dentistry, Dental Caries

\section{INTRODUCTION}

Telemedicine is convenyance of health care across the globe using the information-based technologies and communications systems. ${ }^{1}$ Internet is the foundation of this modern systems of telemedicine as it is beneficial in transporting large amounts of data. ${ }^{2}$ This entire process of networking, sharing digital information, distant consultations, workup, and analysis when applied to field of dentistry is known as "teledentistry". Henceforth, it combines telecommunication with information technology for dental care, consultation, education, and public awareness for inaccessible sections of population. ${ }^{3}$

\section{ORIGIN}

In 1989, at a conference in Baltimore, Teledentistry came into being as a part of the blueprint laid down for dental informatics. ${ }^{4}$ Teledentistry as a subspecialist branch of telemedicine came into being in 1994 , when a military project of the United States Army (U.S. Army's Total Dental Access Project), aimed to provide patient care, dental education. The dental professionals can consult each other even at large distances indirectly reducing total patient care costs, extending dental care to distant and rural areas and offering complete information required for deeper analyses. ${ }^{5}$

\section{IMPORTANCE FOR TELEDENTISTRY}

Teledentistry is the cheapest, fastest, specialized way to provide dental care to the inaccessible areas of a country, and also to unaffordable sections of the community. It has the potential to eliminate the disparities in oral health care, henceforth promoting equity. ${ }^{6}$

\section{INTERNET AS THE BASIS OF TELEDENTISTRY}

Internet is the foundation of teledentistry. The high speed, low cost, documented consultation, simultaneous communication of various participants are an added advantage to this subspecialist branch. Although many short comings are also encountered such as lack of proper training, desire for instant response, misunderstanding due to language issues, privacy concerns which limits its use for delivery of effective health care. ${ }^{7}$

\section{APPROACHES}

There are various approaches for Teleconsultation. Firstly, the "real-time consultation", where videoconferencing takes place among the dental professionals and their patients, located at various sites. They may see, hear, and communicate with one another at one time to have a live interaction. Secondly, the "store-and-forward method", where the exchange of clinical information and static images takes place. The dental practitioner forwards them for consultation and treatment planning to other dentists and waits for a response. It provides marvelous results without any excessive expenditure. The third method is "remote monitoring method," where patients are monitored at a distance and can either be hospital-based or home-based. Fourthly, "near real-time" consultation involves low resolution, low frame rate product that looks like jittery television. Patients are not present during the "consultation." Dentists can share patient information, radiographs, graphical representations of periodontal and hard tissues, therapies applied, laboratory results, tests, remarks, photographs, and 
other information transportable through multiple providers and then after session is over, provides care to the dentist. ${ }^{3,5,8-10}$

\section{REQUIREMENTS \\ TO \\ PRACTICE \\ TELEDENTISTRY}

The teledentistry system consists of a computer with substantial hard drive memory, adequate randomaccess memory, and a speedy processor; an intraoral video camera and a digital camera for the capture of pictures; a modem and an Internet connection. In few cases, a fax machine, scanner, and printer is also a required. For live videoconferencing, Interactive videoconferencing (conducted via plain old telephone system (POTS), satellite, Integrated Services Digital Network (ISDN), into the system is a must. For live group sessions, a multipoint control unit that bridges three or more parties is required. The codec must be able to accommodate audio and visual functions. ${ }^{11}$

\section{TRAINING}

The Instructors of teledentistry must have teaching experience as well as knowledge related to computers and internet. It is a must for them to continuously update themselves. The teledentistry-based education programs are mostly in English. Evidencebased review on applications of teledentistry in various specializations. ${ }^{4-6,12}$

\section{APPLICATIONS IN VARIOUS FIELD OF DENTISTRY}

1. Role in Oral Medicine and Radiology: Although face-to-face oral examination of the patient is more reliable in establishing a definitive diagnosis for oral mucosal pathologies than transmitted descriptive patient data alone. Till the time adequate data transfer of visual and text information occurs, by the examining consultant, the electronic mail may be used for sharing ideas, latest scientific information, and discussing the provisional diagnoses of the patient only. ${ }^{13,14}$

2. Teledentistry in Allied Health Sciences: The local dentist trains the Dental hygienists and dental staff to record case histories when the patient is being treated through teledentistry service. They also increase awareness concerning public health issues associated with access to care with an objective to increase students' knowledge levels and attitudes. ${ }^{15,16}$

3. Role in Prosthodontics: Ignatius $E$ et al. carried out a study to investigate the benefits of videoconferencing for final diagnosis and treatment planning of patients requiring prosthetic or oral rehabilitation. They further stated that this technology has great potential in remote areas. ${ }^{17}$

4. Role in Orthodontics: The low-income families residing in rural areas find it difficult to pay for each visit to the orthodontist. They usually have to travel a long distance to find an orthodontist and skip a day at workplace and school to keep the appointment. Henceforth because of unaffordability, inaccessibility to ortho treatment, many rural, low-income children enter adulthood with "bad teeth" that impair their quality of life. ${ }^{18}$

Teledentistry helps to overcome the above mentioned barriers by reducing the number of inappropriate referrals and enabling dentists to treat more patients themselves. ${ }^{19}$

Mandall et al. also reported in their study that teledentistry is a effective way of positively identifying patients who should be ideally referred to a consultant orthodontist. ${ }^{20}$

5. Role in Oral And Maxillofacial Surgery: Telemedicine can be used for diagnostic assessment of the clinical diagnosis of impacted or semiimpacted third molars, in adequately assessing patients for dentoalveolar surgery with general anesthesia and nasotracheal intubation, pre-operative evaluation in situations in which patient transport is difficult or costly. ${ }^{21-23}$

\section{Role in Pediatric and Preventive Dentistry:} Teledentistry is effective for visual/tactile examinations of dental caries in young children, screening highrisk preschool children for signs of early childhood caries attending daycare centers. ${ }^{2-3,24}$

7. Role in Periodontics: Teledentistry was intially tested for capturing color images of a patient's oral cavity. A 9600 band modem was used to trasmit images from the dental clinic over to Fort Gordon, Georgia, located 120 miles apart. In total, Fifteen periodontal patients were referred to Fort Gordon for perio surgery. Patient were asked to report to Fort McPherson after a week, for suture removal and intra-oral imaging. The colored images captured from the surgical sites were transmitted to Fort Gordon for evaluation by the Periodontist, who performed the surgery. Overall, the patients were satisfied and mentioned that they received better care as well as 
saved from taking a long trip to Fort Gordon. The dentists were also satisfied with their decisions and diagnoses using the same equipment. ${ }^{10}$

8. Role in Oral Pathology: The College of Dentistry (UFCD) affliliated with University of Florida dsegined a format ("Case of the Month") which special focus on clinical oral pathology. A differential diagnosis in the form of a question with correct or incorrect options was developed for a particular case. A detailed description and rationale was also described. Described. The respondents completed an online survey assessing their needs, expectations, attitudes, level of clinical knowledge gained, and experience at the end of presentation. The Results reported that the participants' needs and expectations were met. The biggest drawback was lack of communication between the particpants. ${ }^{25}$

\section{DISCUSSION AND CONCLUSION}

Teledentistry is a method to deliver dental services in rural and remote areas where there is dearth of a specialist consultation. In a developing country like India, which has diverse landmass, massive rural population, and with existing health-care delivery mechanism clubbed with telecommunications technology, could be an ideal setting for effective utilization of teledentistry. ${ }^{26-29}$ General dental surgeon and dental hygienists can be appointed at primary, secondary levels of health care delivery system to provide cost effective dental care. Graduate dentists can be posted at these centres as a part of their internship training module and can be trained for diagnosis and treatment planning of the various cases. The dental colleges have a team of specialist under a common roof, which could in itself serve as hub sites for teledentistry consultation. Every new venture is accompanied with certain shortcomings like the confidentiality of medical and dental information, Concerns arising from the transfer of medical histories and records as well as from general security issues of electronic information stored in computers, problem of "cyberdentist" mushrooming need to be declaimed before teledentistry can rise to its maximum peak and provide effective care to the patients. ${ }^{30-32}$

\section{REFERENCES}

1.Chen JW, Hobdell MH, Dunn K, Johnson KA, Zhang J. Teledentistry and its use in dental education. The Journal of the American Dental Association. 2003; 134(3):342-6.
2. Kopycka-Kedzierawski DT, Billings RJ. Teledentistry in inner-city child-care centres. Journal of telemedicine and telecare. 2006;12(4):176-81.

3. Kopycka-Kedzierawski DT, Billings RJ, McConnochie KM. Dental screening of preschool children using teledentistry: a feasibility study. Pediatric dentistry. 2007;29(3):209-13.

4. Berndt J, Leone P, King G. Using teledentistry to provide interceptive orthodontic services to disadvantaged children. American Journal of Orthodontics and Dentofacial Orthopedics. 2008;134(5):700-6.

5. Bhambal A, Saxena S, Balsaraf SV. Teledentistry: potentials unexplored. J Int Oral Health. 2010;2(3):1-6. 6. Mariño R, Ghanim A. Teledentistry: a systematic review of the literature. Journal of Telemedicine and Telecare. 2013;19(4):179-83.

7. Fricton J, Chen H. Using teledentistry to improve access to dental care for the underserved. Dental Clinics. 2009;53(3):537-48.

8. Bauer JC, Brown WT. The digital transformation of oral health care: Teledentistry and electronic commerce. The Journal of the American Dental Association. 2001;132(2):204-9.

9. Jampani ND, Nutalapati R, Dontula BS, Boyapati R. Applications of teledentistry: A literature review and update. Journal of International Society of Preventive \& Community Dentistry. 2011;1(2):37.

10. Rocca MA, Kudryk VL, Pajak JC, Morris T. The evolution of a teledentistry system within the Department of Defense. InProceedings of the AMIA Symposium 1999 (p. 921). American Medical Informatics Association.

11. Clark GT. Teledentistry: what is it now, and what will it be tomorrow?. Journal of the California Dental Association. 2000;28(2):121-7.

12. Torres-Pereira C, Possebon RS, Simoes A, Bortoluzzi MC, Leao JC, Giovanini AF, Piazetta CM. Email for distance diagnosis of oral diseases: a preliminary study of teledentistry. Journal of Telemedicine and Telecare. 2008 Dec;14(8):435-8.

13. Younai FS, Messadi DV. E-Mail-Based Oral Medicine Consultation. J Calif Dent Assoc. 2000;28(2):144-51.

14. Sanchez Dils E, Lefebvre C, Abeyta K. Teledentistry in the United States: a new horizon of dental care. International journal of dental hygiene. 2004;2(4):161-4.

15. Susan ES. Teledentistry: A new view on oral Health care. J Calif Dent Assoc 2000;28(4):219-25.

16. Cooper BR, Lynnete M, Engeswic M. Knowledge, attitudes and confidence levels of dental hygiene 
students regarding Teledentistry: A pilot study. The Internet Journal of Allied Health Sciences and Practice. Available from: http://ijahsp.nova.edu/articles/vol5num4/pdf/co oper.pdf 2007; 5 (4).

17. Ignatius E, Perala S, Makela K. Use of Videoconferencing for Consultation in Dental Prosthetics and Oral Rehabilitation. J Telemed Telecare 2010;16:467-70.

18. Berndt J, Leone P, and King G. Using teledentistry to provide interceptive orthodontic services to disadvantaged children. Am J Orchid Dentofacial Orthop 2008; 134(5): 700-6.

19. Cook J, Edwards J, Mullings C Stephens C. Dentists' opinions of an online orthodontic advice service. J Telemed Telecare 2001;7(6):334-7.

20. Mandall NA, O'Brien KD, Brady J, Worthington HV, Harvey L. Teledentistry for screening new patient orthodontic referrals. Part 1: A randomised controlled trial. British dental journal. 2005;199(10):659.

21. Duka M, Mihailovic B, Miladinovic M, Jankovic A, Vujicic B. Evaluation of Telemedicine Systems for Impacted Third Molars Diagnosis. Vojnosanit Pregl 2009;66:985-91.

22. Rollert MK, Strauss RA, Abubaker AO, Hampton C. Telemedicine Consultations in Oral and Maxillofacial Surgery. J Oral Maxillofac Surg 1999;57:136-8.

23. Brickley M. Oral Surgery: The Referral System and Telemedicine. Br Dent J 200o;188:384.

24. Amavel R, Cruz-Correia R, Frias-Bulhosa J. Remote Diagnosis of Children Dental Problems Based on Non- Invasive Photographs: A Valid Proceeding. In: Adlassnig KP, Blobel B, Mantas J, Masic I (editors). Medical Informatics in a United and Healthy Europe

Source of support: Nil, Conflict of interest: None declared
2009. Amsterdam (Netherlands): IOS Press; 2009. p. 458-62.

25. Chumbler N R, Cohen D M, Bhattacharyya I, Sweitzer J, Dolan T A. University of Florida College of Dentistry's "Case of the Month": Evaluating a webbased continuing dental education course for clinical oral pathology. J Dent Educ 2007; 71(2): 26o-8.

26. Chang SU, Mulligan R, Polido J, Mah J. Teledentistry in rural California: a USC initiative. J Calif Dent Assoc. 2003 Aug;31.

27. Birnbach JM. The future of teledentistry. Journal of the California Dental Association. 2000 Feb;28(2):141-3.

28. Daniel SJ, Kumar S. Teledentistry: a key component in access to care. Journal of Evidence Based Dental Practice. 2014;14:201-8.

29. Bradley M, Black P, Noble S, Thompson R, Lamey PJ. Application of teledentistry in oral medicine in a community dental service, N. Ireland. British dental journal. 2010 Oct;209(8):399.

30. Mihailovic B, Miladinovic M, Vujicic B. Telemedicine in dentistry (Teledentistry). InAdvances in Telemedicine: Applications in Various Medical Disciplines and Geographical Regions 2011 Mar 22. IntechOpen.

31. Khan SA, Omar H. Teledentistry in practice: literature review. Telemedicine and e-Health. $2013 \mathrm{Jul}$ 1;19(7):565-7.

32. Reddy K. Using teledentistry for providing the specialist access to rural Indians. Indian Journal of Dental Research. 2011;22(2):189.
Cite this article as:

Verma A, Dhall A, Kataria S. Teledentistry: New Tool to Access Dental Care. Int Healthc Res J. 2019;3(1):16-19. doi: 10.26440/IHRJ/0301.04.521067

\section{AUTHOR AFFILIATIONS:}

1. BDS, Graduate Student

2. BDS, MDS, Associate Professor, Department of Public Health Dentistry

Sudha Rustagi College of Dental Sciences \& Research, Kheri More, Village Bhopani, Faridabad, Haryana, India

*Corresponding Author:

Aditi Verma

BDS, Graduate Student

Sudha Rustagi College of Dental Sciences \& Research

Kheri More, Village Bhopani, Faridabad, Haryana, India
For article enquiry/author contact details, e-mail at: $\underline{\text { editor.ihri@gmail.com }}$ 